later, and again by mo in 1925 (Proc. Roy. Soc., B, vol. 98). Their behaviour under the action of staining and fixing reagents is entirely different from that attributed to Golgi bodies by Prof. Gatenby. In fact, when the methods he recommends for the demonstration of Golgi bodies are used, only a distorted image of the later stages can be traced, even by one familiar with these structures in properly preserved material.

It is curious and suggestive that these vesicles, which can be traced through three cell generations, which are described as going to form the cap of the sperm, and are best demonstrated by those methods of fixation regarded as least likely to distort the structure of the cell long before Golgi bodies became fashionable, should be those which are now claimed as the Golgi bodies which can be seen in the living cell. The true Golgi body, according to Prof. Gatenby, is not demonstrable in fixed material if acetic acid is used, and the material requires subsequent treatment for a week or two in osmic acid, or the use of some other drastic method such as those, the use of which is deplored by many histologists, necessary in the case of some preparations of nervous tissues ; deplored because, though they are requisite for the particular purpose in view, they distort the structures to be examined. I see no reason, therefore, for calling a structure which is best demonstrated by the use of a fixative containing a considerable percentage of acetic acid and by rigidly avoiding the methods recommended by Prof. Gatenby, a Golgi body ; particularly as its history and destiny were more clearly shown by other investigators many years before he published his first paper upon the subject.

With regard to the rest of what Prof. Gatenby calls Golgi bodies, I am sorry that he did not give any reasons for his condemnation of my paper (Proc. Roy. Soc., 101; 1927). His assertion that $I$ have been asleep for thirty years I can scarcely regard as bearing upon the validity of my observations. Nor do I see that their truth is affected by my failure to quote papers by a botanist on " mitochondria which even divided."

The observations referred to were briefly as follows. If mixtures containing proteid, peptone, albumose lipins, and other substances found in cells, are treated with a fixative that does not contain acetic acid, structures indistinguishable from the 'Golgi bodies' may be demonstrated if the preparation is dealt with according to Prof. Gatenby's osmic acid method. Moreover, if minute globules of fat are introduced into the solutions, some of the 'Golgi bodies' take up 'a juxta-nuclear position' just as do some of the 'Golgi bodies' in the cell. They do not appear if the lipins are omitted from the mixture. If acetic acid is used in the fixative, the 'Golgi bodies' do not appear either in my mixtures or in the cells. Now all cells, animal and vegetable, contain lipins, chiefly lecithin and kephalin, therefore it would be very surprising if these bodies did not appear in the cells just as they do in the mixtures.

How are Prof. Gatenby's assertions supported? Evidently from his letter there is much disagreement even among the adherents of the Golgi body. But he quotes "the leading English workers" as believing certain things about them. Who are the leading English workers ? Prof. Gatenby's style of writing again makes me doubtful as to his exact meaning, but I rather gather from his letter that he means himself, Dr. Ludford, Dr. Brambell, and Miss Shana King. Surely there are some others! But later on in his courteous criticism when he says, "If Prof. Bose expects other cytologists to accept the view . . . , he is much mistaken," he appears to consider himself justified in speaking for cytologists in general, so perhaps these really are our leaders.

There is one request I would venture to make of Prof. Gatenby, and that is that he would cease to use the word 'inclusions' in describing all structures contained in the cell or even in the cytoplasm. I hope he means something different from what the word may be interpreted as meaning when he uses it thus. The invention of a new word, or trying to give a new meaning to an old word, is always regrettable, though the former proceeding is sometimes unavoidable.

"He strikes no coin, 'tis true, but coins new phrases, And vends them forth as knaves vend gilded counters, Which wise men scorn, and fools accept in payment." (Old Play, quoted by Sir Walter Scott, chap. xv. "The Monastery.")

Charles Watker.

The University, Liverpool, Jan. 10.

\section{A Dark Space in High-frequency Discharges.}

Krrchner (Ann. d. Phys., 77, 287 ; 1925), Gill and Donalson (Phil. Mag., 2, 129; 1925), and Wood and Loomis (NATURE, Oct. 8, 1927) have shown that a glow discharge can be produced in vacuum tubes at very low pressures, provided the exciting current has a frequency of the order of $4 \times 10^{7}$.

Some experiments were carried out by me in which a $17 \mathrm{~cm}$. spherical bulb, fitted with both internal and external electrodes, was excited at low pressures by a short-wave oscillation generator having a frequency of $3.8 \times 10^{7}$. Discharges of about equal brightness were obtained with either pair of electrodes.

When the internal electrodes (made of sheet aluminium $3 \mathrm{~cm} . \times 3 \mathrm{~cm}$.) were used, a well-defined dark space appeared surrounding each electrode. This dark space had the appearance of the well-known Crookes's dark space but differed decidedly in thickness. When the pressure was such that a 25,000 -volt transformer produced a $12 \mathrm{~cm}$. Crookes's dark space, this new dark space had a thickness of only $2 \mathrm{~cm}$. The thickness of this new dark space proved to be more or less inversely proportional to the pressure, for on decreasing the pressure, the thickness increased to about $3.5 \mathrm{~cm}$. At the minimum pressure used, the transformer produced no trace of $\mathrm{a}_{\mathrm{b}}$ discharge in the tube. The dark space could also be seen when the tube was excited by means of the external electrodes.

According to Kirchner, the high-frequency discharge results from a to-and-fro motion of electrons in the rapidly alternating field, the distance between electrodes necessarily being greater than the amplitude of the to-and-fro motion of the electrons. On this hypothesis a dark region near the electrodes is to be expected, for if the mean position of the electron is less than half its amplitude of oscillation from an electrode, the electron will be removed from the field by the electrode. To account for the sharp boundary of the dark space, one must recall that the strength of the electric field in these high-frequency discharges is not large, so that only in the vicinity of its mean position will the electron have sufficient energy to excite radiation. It is probable that the change with pressure is due to an increase in potential, for lowering the pressure decreases the number of available electrons, and if we consider the to-and-fro motion of the electrons as a kind of displacement current, decreasing the number of electrons will change the potential across the tube.

Mount Wilson Observatory, SinclaIR SMITH. Dec. 20, 1927.

No. 3038 , VoL. 121] 